\title{
Informática jurídica, lenguajes documentales y técnica legislativa
}

JOSEP AGUILÓ REGLA

Este trabajo, que trata de presentar una teoría general de los sistemas automáticos de documentación jurídica, se propone tres objetivos básicos. El primero es el de proponer una determinada sistemática desde la que poder abordar de forma coherente y no excesivamente fragmentada toda la problemática que gira en torno a la informática jurídica documental. El segundo es el de aportar una terminología más rigurosa que permita superar imprecisiones y ambigüedades presentes en el lenguaje del proceso de datos jurídicos. Y el tercero es el de mostrar algunas limitaciones y disfunciones concurrentes en la documentación jurídica automática, así como proponer algunas vías de superación de las mismas.

Para la consecución de estos tres objetivos he dividido el trabajo en cinco capítulos. En el primero de ellos he introducido Algunas nociones informáticas con el fin de aclarar el uso que a lo largo del trabajo se hace de ciertos términos y expresiones. Así, entre otras, se repasan las nociones de sistemas de información; campo, registro y fichero; magnitudes aplicables a los ficheros; proceso y organización de ficheros, y base de datos y banco de datos.

En el capítulo segundo, que gira en torno a lo que podría llamarse «aspectos estructurales» de los sistemas automáticos de documentación jurídica, he abordado el estudio de los datos jurídicos, lo que ha implicado detenerse, por un lado, en las características jurídicas y documentales de la legislación, la jurisprudencia y la doctrina jurídica, y, por otro, en las propiedades y la organización de los ficheros que contienen 
a los referidos datos. Asimismo, en este capítulo, he abordado cuestiones tales como el problema del análisis y el formato de los documentos jurídicos, los métodos de indexación de los documentos, los elementos de la ecuación de consulta (las variables, los operadores lógicos -conjunción, disyunción incluyente, disyunción excluyente y negación-, los operadores sintácticos - contigüidad fija, contigüidad libre, frase, párrafo y control de orden y distancia-, los paréntesis y las funciones - de enmascaramiento, selectivas, thesaurus y de ayuda-) y las reglas sintácticas que rigen su uso (secuencias autorizadas).

En relación con lo anterior, el capítulo supone un cambio de perspectiva. En él he tratado de afrontar todas las cuestiones de naturaleza lingüística que plantea el proceso de datos en lenguaje natural, en general, y de datos jurídicos, en particular. Para ello, tras aclarar el uso que se hace en el texto de ciertos términos tomados de la lingǘstica, he procurado analizar el lenguaje jurídico o, mejor dicho, el vocabulario del lenguaje de los documentos jurídicos, aislando los distintos subconjuntos de términos que pueden distinguirse en función del papel y de la relevancia de los mismos a la hora de construir un lenguaje documental en el campo del Derecho. Asimismo, he procurado precisar la noción de lenguaje documental y mostrar las distintas posibilidades de coordinación lingüística que estos lenguajes ofrecen. Todo ello desemboca, finalmente, en un estudio pormenorizado de los thesauri. Así, aparte de intentar aclarar su concepto y de mostrar las clasificaciones más importantes, me he detenido en el análisis de sus dos elementos estructurales: el vocabulario (criterios de selección de las palabras clave, representación de las relaciones sintagmáticas y reglas gramaticales que le son aplicables) y las relaciones paradigmáticas (tanto semánticas -lógicas y sistemáticas - como morfológicas).

En el capítulo cuarto, he tratado de mostrar y describir un número suficientemente representativo de sistemas automáticos de documentación jurídica existentes y realmente operativos. Ello me ha llevado a dar un repaso a la situación de la informática jurídica en Italia, Francia, Estados Unidos y España.

En el capítulo quinto, me he centrado en el estudio de la legislación como dato jurídico. La razón de ello radica en que en la documenta- 
ción automática de legislación subsisten problemas y disfunciones que no se presentan en la documentación de los otros datos jurídicos por lo que me ha parecido oportuno otorgarles un tratamiento autónomo. La idea principal que se recoge en este capítulo es la de que muchas de las disfunciones que concurren en la documentación de legislación tienen su origen en insuficiencias del objeto de la automatización y no del instrumento. Es decir, son insuficiencias del derecho y no de la informática; lo cual lleva a pensar que la contribución informática a la documentación de legislación ha llegado a un cierto límite más allá del cual no cabe esperar ningún cambio relevante. A partir de este planteamiento, se vincula a la informática jurídica legislativa tanto con la técnica legislativa como con la informática parlamentaria. La primera de estas vinculaciones viene dada por el hecho de que, como se muestra en el texto, una de las vías para superar estas disfunciones es la modificación de la técnica legislativa. En otras palabras, se sostiene que dentro del test de calidad que parece que todo texto legal debería pasar hay que incluir también requisitos en vistas a su futura documentación. A este planteamiento responden los apartados de recomendaciones de técnica legislativa que se hacen tanto en el nivel de la racionalidad lingüística (destinadas a controlar, por un lado, el vocabulario utilizado por el legislador, ya que de él se extraerá el vocabulario documental; y, por otro, el tamaño, la estructura y el contenido de los artículos, ya que éstos constituirán las unidades documento del sistema documental) como en el nivel de la racionalidad jurídico-formal (destinadas a alcanzar el objetivo de determinar el sistema jurídico vigente y, para ello, tratan, por un lado, de eliminar el sobrante de enunciados normativos, y por otro, de conseguir integraciones autorizadas de los textos vigentes).

La segunda de las referidas vinculaciones viene dada porque entre la informática parlamentaria y la informática jurídica legislativa puede definirse una relación sistemática vertical, donde la primera constituye el miembro superior y la segunda el miembro inferior. La importancia de esta relación se debe no tanto a razones de tipo conceptual, cuanto a razones de tipo estratégicos: si los parlamentos o sus servicios de documentación empiezan a gestionar sistemas automáticos de documentación de legislación, parece razonable pensar que será más fácil implicar al legislador en la superación de las disfunciones antes aludidas. 
Este es, pues, aparte de una introducción, un capítulo de conclusiones y un apéndice bibliográfico, el esquema sobre el que se sustenta la presente tesis. Pero aquí, no quiero dejar de referirme a dos cuestiones que, si bien no aparecen expresamente desarrolladas en la tesis, si la subyacen de manera tácita. La primera concierne a la relevancia del tema. No se trata, evidentemente, de justificar la importancia de la informática jurídica, pues darla por supuesto no resulta ni mucho menos arriesgado; sino más bien de justificar la importancia de la informática jurídica documental frente a otros sectores de la informática jurídica. Ello es relevante porque, como se dice en la Introducción, desde hace algún tiempo, en la literatura iusinformática se observa una cierta tendencia a desplazar el centro de atención de la informática jurídica documental a la informática jurídica decisional (sistemas expertos). De alguna de esta literatura parece derivarse, además, la impresión de que los sistemas expertos en el campo del Derecho constituirían, de algún modo, una superación de los sistemas automáticos de documentación jurídica, dado que para construir un sistema experto sobre una rama del derecho es condición necesaria disponer de todos los enunciados jurídicos válidos que forman esa rama; esto es, es condición necesaria haber resuelto el problema documental. Pero, en mi opinión, tal impresión resulta engañosa. En efecto, los sistemas expertos hasta hoy diseñados en el campo del Derecho operan sobre subsistemas jurídicos (especialmente seleccionados) en los que llegar a determinar el conjunto de enunciados válidos no se presenta como problemático. Por ello, me parece que los sistemas expertos no superan el problema documental. Resaltar esto es importante por una razón: con sistemas expertos o no, el objetivo documental de llegar a determinar el conjunto de enunciados que expresan el sistema jurídico vigente no se ha alcanzado aún y, en consecuencia, difícilmente puede hablarse de superación de la informática jurídica documental. Naturalmente, siempre cabe abandonar el referido objetivo y fijarse otros nuevos, pero, en mi opinión, es importante no olvidarse del carácter instrumental de la informática y, por tanto, no perder de vista a la demanda final. Y, en este sentido, a mi juicio, la demanda de «documentación automática» es hoy por hoy muy superior a la demanda de «interpretación automática». 
La segunda de estas cuestiones está relacionada con el papel de la teoría del Derecho dentro de la informática jurídica documental. Lo interesante aquí es mostrar que cuando la informática jurídica documental se propone objetivos realmente ambiciosos, entonces ineludiblemente se llega a un punto en el que los problemas que se presentan abandonan el ámbito técnico-informático para situarse en el interior de la teoría del Derecho y que es en este terreno en el que los juristas podemos contribuir al progreso de este sector. Si se da un repaso somero al presente trabajo se observará que, de manera más o menos desarrollada, han ido apareciendo cuestiones tales como la interpretación de la ley y las fuentes del Derecho, las relaciones entre los conceptos jurídicos, el lenguaje jurídico, la contaminación legislativa, la relación entre enunciado normativa y norma, los tipos de enunciados en el Derecho, los conceptos de ordenamiento jurídico y sistema jurídico, la dinámica jurídica y la derogación, etc.; todas ellas cuestiones centrales de la teoría del derecho. Con todo ello, lo que trato de poner de manifiesto es, por un lado, que el desarrollo de una adecuada teoría del derecho es fundamental para el progreso de la informática jurídica documental, y, por otro, que ésta última constituye una nueva vía desde la que poder abordar viejos problemas, así como un banco de pruebas para valorar la resistencia de las distintas teorías jurídicas. 